Borneo Journal of Sciences \& Technology, 3(2): 20-23

DOI: http://doi.org/10.3570/bjost.2021.3.2-04

e-ISSN: 2672-7439

(C) 2018, UCTS Publisher.

Submitted: $03^{\text {rd }}$ May 2021

Accepted: $08^{\text {th }}$ June 2021

Published: $31^{\text {st }}$ July 2021

\title{
Antioxidant and Antityrosinase Properties of Rhodomyrtus tomentosa Extract
}

\author{
Mohd Syafiq Abdullah \\ School of Engineering and Technology, University College of Technology Sarawak (UCTS), \\ 96000 Sibu, Sarawak, Malaysia
}

\begin{abstract}
In traditional Thai medical practice, Rhodomyrtus tomentosa (R. tomentosa) has been used broadly in skincare products. The potency to brighten skin, defy aging and beautify skin may be attributed to its antioxidant and anti-tyrosinase activity. Hence, this study evaluates the antioxidant and anti-tyrosinase activity of $R$. tomentosa leaf, stem, and fruit extracts. Methanolic extract of $R$. tomentosa flower exhibited the highest radical scavenging activity (IC50 $95 \mu \mathrm{g} / \mathrm{mL}$ ), total phenolic content (100.467 mg GAE/g), and tyrosinase inhibitory activity (IC50 0.1 $\mu \mathrm{g} / \mathrm{mL}$ ). The findings suggest that extract has proven its potential as an anti-hyperpigmentation agent due to the phenolic compound (piceatannol) in such species that can be advantageous to cosmeceutical applications.
\end{abstract}

Keywords: Rhodomyrtus tomentosa, Antioxidant, TPC, Antityrosinase

\section{INTRODUCTION}

According to Hamid et al., [1], R. tomentosa was recognized by the scientific project "Agrofolio" as one of 240 "Neglected and Underutilized Crop Species" in Vietnam, China, Thailand, and Cambodia. R. tomentosa is a member of the Myrtaceae family. It is an evergreen shrub native to Southeast Asia, where It blooms profusely and produces dark-purple edible bell-shaped fruits with rose-pink flowers [2]. As pests and diseases rarely infest it, this plant is considered of low maintenance [3].

Parts of the plant, such as stem, leaves, and fruits, have been advantageous as medical alternatives [4]. Historically, $R$. tomentosa has been acknowledged for being beneficial as traditional Thai, Vietnamese, Chinese and Malaysian medicine, especially in treating colic diarrhea, wounds, heartburn, abscesses, gynecopathy, and boosting the immune system [1,5]. Moreover, Limsuwan et al., [6] suggested that ethanolic extract of $R$. tomentosa demonstrates exceptional antibacterial activity whilst the main phenolic compound contained in $R$. tomentosa fruits was piceatannol, a promising health-promoting stilbene ingredient. Nojima et al., [7] and Hiranrat [8] reported that piceatannol is recognized for its use as free radical scavenger, tyrosinase inhibitors, and skin brightening agent. However, information concerning the tyrosinase inhibitory activity of $R$. tomentosa is still lacking.

Therefore, in line with recent research trends which focuses on sustainable and renewable materials, the present study is specially designed to leverage the potential of Rhodomyrtus tomentosa ( $R$. tomentosa) extract as tyrosinase inhibitor by evaluating their properties and characteristics.

\section{MATERIALS AND METHODS}

$R$. tomentosa leave, fruit, and flower were collected from nearby Marang, Terengganu. The following characteristics can identify this species; the seedlings are partially hairy and pubescent; the leaves are oval, round, or obtuse at the apex, hairy on the lower surface, $7 \mathrm{~cm}$ long, $4 \mathrm{~cm}$ wide, $0.5 \mathrm{~cm}$ long of petiole, and petals are pink or purplish-red. The fruits are berries, green when they are young, and dark purple when they are ripe, fleshy, sweet, and fragrant. This species has many (40-45) tiny triangular seeds embedded in edible flesh, and fruit-eating birds and mammals spread the seeds. All chemical reagents used were of analytical grades.

\section{Preparation of Rhodomyrtus tomentosa Extract}

Preparation of $R$. tomentosa extracts was conducted according to method adopted from Narayanaswamy et al., [9]. Various parts (leave, fruit and flower) of $R$. tomentosa were thoroughly washed with distilled water and dried under shade. The dried materials were ground separately into powder and used for further experimentation. Then, adapting from Hiranrat and Mahabusarakam, [10], with hexane and methanol, the powder was percolated at room temperature for a day.

Corresponding Author: Mohd Syafiq Abdullah. School of Engineering and Technology, University College of Technology Sarawak (UCTS). Email: mohdsyafiq@ucts.edu.my 
At temperature below $60^{\circ} \mathrm{C}$, both plant samples were sonicated for 30 minutes. This process was repeated thrice. Both hexane and methanol extract was then filtered and evaporated at $60^{\circ} \mathrm{C}$ by using a vacuum rotary evaporator. To produce chloroform and ethyl acetate extracts, the concentrated methanol extract was suspended in water, partitioned with chloroform and ethyl acetate, and evaporated in a vacuum.

\section{Antioxidant Assays}

The antioxidant activity of plant material was evaluated by employing the following methods. DPPH radical scavenging assay [11]. DPPH (2, 2-diphenyl picryl hydrazyl) is a commercially available, commonly used, stable free radical that can accept hydrogen from antioxidant, converted into di-phenyl hydrazine, which is yellow in colour. Scavenging potential of plant extracts was measured at $520 \mathrm{~nm}$, indicated by the degree of discoloration of purple to yellow. $5 \mathrm{Hl}$ of plant extract was added to $195 \mathrm{Hl}$ of DPPH solution (0.1 mM DPPH in methanol) in a microtitre plate. The reaction mixture was incubated at $25^{\circ} \mathrm{C}$ for 10 minutes prior to absorbance measurement at $520 \mathrm{~nm}$. The DPPH with corresponding solvents (without plant material) serves as a control, whereas the methanol with respective plant extracts is blank. The DPPH radical scavenging activity of the plant extract was calculated using the following equation.

\section{Inhibition of DPPH radical $(\%)=$ $\frac{A_{0}-A_{1}}{A_{0}} \times 100$}

Where, $\mathrm{A}_{0}$ was the absorbance of control reaction and $A_{1}$ was the absorbance in the presence of test or standard sample.

\section{Determination of Total Phenolic Content}

The Folin-Ciocalteu method was used to assess the total phenolic content of the extract [12]. To summarise, $200 \mu \mathrm{L}$ of crude extract $(1 \mathrm{mg} / \mathrm{mL})$ were made up to $3 \mathrm{~mL}$ with distilled water, then thoroughly mixed with $0.5 \mathrm{~mL}$ Folin-Ciocalteu reagent for 3 minutes, followed by the addition of $2 \mathrm{~mL}$ of $20 \%$ (w/v) sodium carbonate. The mixture was left to sit for another 60 minutes in the dark before being checked for absorbance at $650 \mathrm{~nm}$. The calibration curve was used to measure the total phenolic content, expressed as mg of gallic acid equivalent per $g$ dry weight.

\section{Tyrosinase Inhibitory Activity}

The inhibitory effect of $R$. tomentosa on tyrosinase activity was calculated spectrophotometrically with the degree of inhibition of mushroom tyrosinase-catalyzed oxidation of 1-DOPA, as described by Senol et al., [13]. Samples were mixed with $40 \mu \mathrm{L}$ L-DOPA and $80 \mu \mathrm{L}$ potassium phosphate buffer ( $\mathrm{pH} 6.8$ ). Finally, $40 \mu \mathrm{L}$ of tyrosinase $(200 \mathrm{U} / \mathrm{mL})$ was added to the wells. LDOPA and tyrosinase were solved in buffer. The inhibition of tyrosinase was determined at $475 \mathrm{~nm}$. Kojic acid was the reference inhibitor substance. The tyrosinase inhibitory activity was calculated using the following formula.

Inhibition of tyrosinase activity $(\%)=\frac{A_{\text {control }}-A_{\text {gample }}}{A_{\text {control }}} \times 100$

Where $\mathrm{A}_{\text {control }}$ was the absorbance of control reaction and $\mathrm{A}_{\text {sample }}$ was the absorbance in presence of test or standard sample.

\section{Statistical Analysis}

MINITAB Release 14, statistical software for Windows, version 14.12.0, was used to analyse the data (Minitab Inc., USA). The findings are expressed as the average of three replicates plus standard deviation. ANOVA was used to calculate mean differences.

\section{RESULTS AND DISCUSSION}

\section{Antioxidant Activity}

As depicted in Table 1, the ability of different $R$. tomentosa extract to scavenge free radical may be visualized as the following order; (i) methanol>chloroform>ethyl acetate $>$ hexane and (ii) flower $>$ fruit $>$ leave. Methanol extract of $R$. tomentosa flower had the lowest value of $\mathrm{IC}_{50}$ and therefore, such extract can be considered as the best antioxidant. Due to the capability of solvent to extract different types of compounds, different solvent extraction resulted in different antioxidant activity. According to Abd Hamid et al., [1] and Siddhuraju and Becker, [14], the ability to give away hydrogen atoms and react with free radicals can be affected by the concentration of compounds present in the extracts. Hypothetically, the higher the polyphenol present in the extract, the higher antioxidant activity. In this study, the findings are agreeable with studies by Abd Hamid et al., [1] and Maskam et al., [15] where high antioxidant activity in DPPH assay were observed in methanol extract. Antioxidant activities may be also attributed by the characteristic of phenolic compounds. The fact that phenolic compounds have a lot of phenolic hydroxyl groups could explain their ability to scavenge free radicals. Phenols donate hydrogen to radicals and produce phenoxide radical.

Likewise, Bazzaz et al., [16] also suggested that antioxidant capacity is depending on composition of 
phenolic contents in the extracts. Hence, in this study, a positive correlation between antioxidant activity and total phenolic content can be developed as the highest antioxidant activity was observed in methanol extract of R. tomentosa flower, which also exhibited highest total phenolic content. Based on Table 1, the order of total phenolic content for the different extracts also can be established as methanol > chloroform > ethyl acetate > hexane. Moreover, these results also suggested that parts of the plant were responsible for different total phenolic content, where the flower had higher phenolic compound than fruit and leave.

\section{Antityrosinase Activity}

Table 1 shows that the methanol extracts of $R$. tomentosa were also better than other extracts in inhibiting tyrosinase activity. All methanol extracts presented $\mathrm{IC}_{50}$ values between 0.1 and $0.8 \mathrm{mg} / \mathrm{mL}$. In this study, methanol extract of $R$. tomentosa flower had the lowest $\mathrm{IC}_{50}$ value and was recognized as the best tyrosinase inhibitor, followed by methanol extract of the $R$. tomentosa fruit. Presumably, methanol extract of $R$. tomentosa had substantial amount of piceatannol. Piceatannol is a major phenolic compound found in $R$.

Table 1: Antioxidant Activity, Total Phenolic Content and Antityrosinase Activity of Rhodomyrtus tomentosa

\begin{tabular}{|c|c|c|c|c|}
\hline Extract & Part of plant & $\begin{array}{c}\mathrm{DPPH} \mathrm{IC}_{50} \\
(\mu \mathrm{g} / \mathrm{mL})\end{array}$ & TPC (mg GAE/g) & $\begin{array}{l}\text { Antityrosinase } \\
\mathrm{IC}_{50}(\mathrm{mg} / \mathrm{mL})\end{array}$ \\
\hline \multirow{3}{*}{ Methanol } & Leaf & 255 & $65.432 \pm 0.04$ & $0.8 \pm 0.23$ \\
\hline & Fruit & 107 & $88.354 \pm 0.10$ & $0.5 \pm 0.12$ \\
\hline & Flower & 95 & $100.467 \pm 0.01$ & $0.1 \pm 0.13$ \\
\hline \multirow{3}{*}{ Chloroform } & Leaf & 411 & $38.534 \pm 0.32$ & $1.2 \pm 0.09$ \\
\hline & Fruit & 230 & $55.565 \pm 0.12$ & $1.0 \pm 0.13$ \\
\hline & Flower & 189 & $72.232 \pm 0.12$ & $0.8 \pm 0.14$ \\
\hline \multirow{3}{*}{ Ethyl Acetate } & Leaf & 723 & $28.785 \pm 0.09$ & $1.2 \pm 0.11$ \\
\hline & Fruit & 669 & $38.756 \pm 0.17$ & $1.1 \pm 0.21$ \\
\hline & Flower & 510 & $46.564 \pm 0.11$ & $1.0 \pm 0.14$ \\
\hline \multirow{3}{*}{ Hexane } & Leaf & 943 & $23.483 \pm 0.01$ & $1.5 \pm 0.09$ \\
\hline & Fruit & 802 & $29.657 \pm 0.04$ & $1.4 \pm 0.13$ \\
\hline & Flower & 687 & $32.867 \pm 0.10$ & $1.1 \pm 0.17$ \\
\hline
\end{tabular}

$\mathrm{IC}_{50}$ value is defined as the effective concentration of extract at which $50 \%$ of the tyrosinase enzyme are inactivated.

\section{Total Phenolic Content}

This study shows that methanol was the best solvent to extract phenolic compounds from $R$. tomentosa. The solubility of phenolic and flavonoid compounds depends verily on the conjugation of the aromatic rings, glycosidic form and side chain such as hydroxyl. The hydroxyl group attached to one molecule determines its polarity and solubility in alcohols or aqueous where polar molecules are soluble in polar solvents and the other way round. Visht and Chaturvedi [17] indicated that the ability of polar solvent become soluble can be attributed to the hydrogen bond formation which is a property of dipole interaction forces. In this study, the results pointed out that the phenolic compound from $\mathrm{R}$. tomentosa was polar, resulting in its highest TPC in methanol extract. In tandem with the studies by Abd Hamid et al., [1], Addai et al., [18] and Ghasemzadeh et al., [19], methanol was the most excellent solvent in extracting phenolic compounds from plants. tomentosa [3,6], and has been proven to be very excellent against mushroom tyrosinase [20].

\section{CONCLUSION}

This research indicates that plants may be a valuable source for new chemotherapeutic and antioxidant agents. Extensive research, either in vitro or in vivo, should be conducted to decide whether it is safe to be used in any applications such as cosmeceutical. The current results will help to provide a basis for further research on $R$. tomentosa and the potential identification of new biologically active compounds with therapeutic and anti-pigmentation properties.

\section{ACKNOWLEDGEMENT}

This project is supported under University College of Technology Sarawak internal research grant (UCTS/RESEARCH/<4/2018/04>(01) 


\section{Antioxidant and Antityrosinase Properties of Rhodomyrtus tomentosa Extract}

\section{REFERENCES}

[1] Abd Hamid, H. A. Z. R. U. L. R. I. Z. A. W. A. T. I., Mutazah, S. S. Z. R., \& Yusoff, M. M. (2017). Rhodomyrtus tomentosa: a phytochemical and pharmacological review. Asian J. Pharm. Clin. Res., 10(1), 10-16.

[2] Winotai, A., Wright, T., \& Goolsby, J. A. (2005). Herbivores in Thailand on Rhodomyrtus tomentosa (Myrtaceae), an invasive weed in Florida. Florida Entomologist, 88(1), 104-105.

[3] Lai, T. N. H., André, C., Rogez, H., Mignolet, E., Nguyen, T. B. T., \& Larondelle, Y. (2015). Nutritional composition and antioxidant properties of the sim fruit (Rhodomyrtus tomentosa). Food chemistry, 168, 410-416.

[4] Lim, T. K. (2012). Rhodomyrtus tomentosa. In Edible medicinal and non medicinal plants (pp. 732-737). Springer, Dordrecht.

[5] Do, T. (2011). Medicine Plants and Remedies of Vietnam. Hanoi: Thoi Dai Publisher.

[6] Limsuwan, S., Trip, E. N., Kouwen, T. R., Piersma, S., Hiranrat, A., Mahabusarakam, W., ... \& Kayser, O. (2009). Rhodomyrtone: a new candidate as natural antibacterial drug from Rhodomyrtus tomentosa. Phytomedicine, 16(67), 645-651.

[7] Nojima, J., Murakami, T., \& Kiso, A. P. (2007). 4'-O- $\beta$-D-glucopyranoside for antioxidants, antiinflammation agents, skinlightening agents, antiaging agents, tyrosinase inhibitors, and skin cosmetics. JP Patent JP2007223919A, 6.

[8] Hiranrat, A. (2010). Chemical constituents from Rhodomyrtus tomentosa (Action) hassk. and antibacterial activity (Doctoral dissertation, Prince of Songkla University Faculty of Science (Organic Chemistry)).

[9] Narayanaswamy, N., Duraisamy, A., \& Balakrishnan, K. P. (2011). Screening of some medicinal plants for their antityrosinase and antioxidant activities. Int. J. PharmTech Res, 3, 1107-1112.

[10] Hiranrat, A., \& Mahabusarakam, W. (2008). New acylphloroglucinols from the leaves of Rhodomyrtus tomentosa. Tetrahedron, 64(49), 11193-11197. scavenging assay (Mensor et al., 2001)

[11] Mensor, L. L., Menezes, F. S., Leitão, G. G., Reis, A. S., Santos, T. C. D., Coube, C. S., \& Leitão, S. G. (2001). Screening of Brazilian plant extracts for antioxidant activity by the use of DPPH free radical method. Phytotherapy research, 15(2), 127130.

[12]Kaur, C., \& Kapoor, H. C. (2002). Anti-oxidant activity and total phenolic content of some Asian vegetables. International Journal of Food Science \& Technology, 37(2), 153-161.

[13] Senol, F. S., Orhan, I. E., Ozgen, U., Renda, G., Bulut, G., Guven, L., ... \& Sekeroglu, N. (2016). Memory-vitalizing effect of twentyfive medicinal and edible plants and their isolated compounds. South African Journal of Botany, 102, 102-109.

[14] Siddhuraju, P., \& Becker, K. (2003). Antioxidant properties of various solvent extracts of total phenolic constituents from three different agroclimatic origins of drumstick tree (Moringa oleifera Lam.) leaves. Journal of agricultural and food chemistry, 51(8), 2144-2155.

[15] Maskam, M. F., Mohamad, J., Abdulla, M. A., Afzan A., \& Wasiman. I. (2014). Antioxidant activity of Rhodomyrtus tomentosa (Kemunting) fruits and its effect on lipid profile in inducedcholesterol New Zealand white rabbits. Sains Malaysiana, 43(11), 1673-1684.

[16] Bazzaz, B. S. F., Khayat, M. H., Emami, S. A., Asili, J., Sahebkar, A., \& Neishabory, E. J. (2011). Antioxidant and antimicrobial activity of methanol, dichloromethane, and ethyl acetate extracts of Scutellaria litwinowii. ScienceAsia, 37(4), 327-334.

[17] Visht, S., \& Chaturvedi, S. (2012). Isolation of natural products. Journal of Current Pharma Research, 2(3), 584.

[18] Addai, Z. R., Abdullah, A., \& Mutalib, S. A. (2013). Effect of extraction solvents on the phenolic content and antioxidant properties of two papaya cultivars. Journal of Medicinal Plants Research, 7(46), 3354-3359.

[19] Ghasemzadeh, A., Jaafar, H. Z., \& Rahmat, A. (2011). Effects of solvent type on phenolics and flavonoids content \& antioxidant activities in two varieties of young ginger (Zingiber officinale Roscoe) extracts. Journal of medicinal plants research, 5(7), 1147-1154.

[20] Yokozawa, T., \& Kim, Y. J. (2007). Piceatannol inhibits melanogenesis by its antioxidative actions. Biological \& Pharmaceutical Bulletin, 30(11). 